\title{
Dynamics and succession of plankton communities with changing nutrient levels in tropical culture ponds of whiteleg shrimp
}

\author{
Veronica Fernandes, Elaine A. Sabu, Mamatha S. Shivaramu, \\ Maria Judith B. D. Gonsalves, Rayadurga A. Sreepada*
}

Aquaculture Laboratory, Biological Oceanography Division, CSIR-National Institute of Oceanography (CSIR-NIO), Dona Paula, Goa 403 004, India

\begin{abstract}
Optimal water quality is a prerequisite for the economic and environmental sustainability of shrimp aquaculture. The dynamics and succession of phytoplankton and microzooplankton assemblages and their interrelationship with water-quality parameters in 2 commercial ponds growing whiteleg shrimp Litopenaeus vannamei in south-western coastal India were assessed through periodic sampling during $96 \mathrm{~d}$ of culture. Of the many centric diatoms that were encountered during the initial stages of culture in nitrogen-rich conditions, only 2 dominant species, both belonging to Thalassiosira, persisted throughout the progression of the culture to produce a healthy bloom (up to $6 \times 10^{6}$ cells $^{-1}$ ). Blooms of Thalassiosira spp. contributed significantly to the increased phytoplankton biomass towards the end of culture period, with a concomitant decrease in concentrations of ammonia and nitrate. The succession of pennate diatoms such as Nitzschia closterium, Pleurosigma elongatum and Thalassionema nitzschioides in moderate abundance was also discernible. Results of canonical correspondence analyses revealed that the progression of a diatom bloom, the emergence of dinoflagellates and the occurrence of intermittent blooms of the mixotrophic flagellate Eutreptiella marina were closely linked to factors such as higher temperature, salinity and phosphate concentration. Grazing by the herbivorous-bacterivorous ciliate communities may have controlled the blooms of undesirable groups of phytoplankton, ensuring better shrimp growth, higher survival and a lower food conversion ratio. Effective uptake of ammonium and nitrate by the blooming diatoms and phytoflagellates possibly prevented nutrient concentrations from reaching toxic levels, thereby generating an eco-friendly aquaculture water discharge into the adjacent ecosystem.
\end{abstract}

KEY WORDS: Diatoms $\cdot$ Microzooplankton $\cdot$ Dinoflagellate $\cdot$ Nutrients $\cdot$ Diversity $\cdot$ Canonical correspondence analysis $\cdot$ Litopenaeus vannamei

\section{INTRODUCTION}

Aquaculture of the whiteleg shrimp Litopenaeus vannamei (Boone, 1931) has expanded tremendously in the last decade, with a reported worldwide production of ca. 4.16 million t in 2016, which was $53 \%$ of total shrimp and prawn production (FAO 2018). Most whiteleg shrimp production is in tropical and subtropical areas of the world, mainly from Asian countries such as China, Thailand, Vietnam, Bangladesh,

${ }^{*}$ Corresponding author: sreepada@nio.org
Indonesia and India. The obvious merits of $L$. vannamei, such as high density tolerance, adaptability to variable environmental conditions (salinity and temperature) and relatively fast growth during short culture periods (Ponce-Palafox et al. 1997, Argue et al. 2002, Roy et al. 2010), have made it the most soughtafter shrimp species for commercial cultivation.

Good water quality is essential for achieving optimal shrimp growth and yield and is a prerequisite for sustainable shrimp farming. With the progression of

() The authors 2019. Open Access under Creative Commons by Attribution Licence. Use, distribution and reproduction are unrestricted. Authors and original publication must be credited. 
culture, however, the water quality in shrimp ponds tends to deteriorate due to higher shrimp biomass and accumulation of organic matter from uneaten feed, feces and metabolites (Santhana Kumar et al. 2017, Ni et al. 2018). It has been reported that only $15 \%$ of the applied feed is transformed into shrimp biomass, whilst the remainder goes into the water and sediment (Briggs \& Funge-Smith 1994). The deterioration in water quality as a consequence of nutrient build-up has been identified as a potential cause of disease outbreak in shrimp ponds (SánchezMartínez et al. 2007, Joshi et al. 2014)

To improve economic sustainability of shrimp culture, high-intensity grow-out systems with zerowater exchange have been developed (Boyd 1999). However, these systems generate effluents typically enriched in suspended solids, nutrients, chlorophyll $a$ (chl a) and high biochemical oxygen demand (PáezOsuna 2001a,b). Shrimp farm wastewater discharges in conjunction with municipal and agricultural effluents have the potential to contribute to eutrophication in the coastal environment (Burford \& Williams 2001, Páez-Osuna et al. 2003, Lacerda et al. 2006, Mohanty et al. 2018). Shrimp-farming industries, therefore, are under increasing pressure to improve environmental sustainability. Since intensive shrimp aquaculture involves the input of various feeds, fertilizers and chemicals that compromise water quality, the use of bio-indicators in conjunction with physicochemical variables to assess water quality may be beneficial.

Phytoplankton are natural biota in shrimp aquaculture ponds, and their abundance and composition are controlled by both biotic and abiotic factors. Phytoplankton are ingested by penaeid shrimps along with a variety of detrital aggregates (Dall 1968, Varadharajan \& Pushparajan 2013). However, not all phytoplankton groups are desirable, as the development and blooming of harmful and toxin-producing species of cyanobacteria and dinoflagellates can negatively affect shrimp growth, survival rate and net productivity (Alonso-Rodriguez \& Páez-Osuna 2003, Songsangjinda et al. 2006, Casé et al. 2008, Keawtawee et al. 2012). Diatoms are known to enhance shrimp growth, and a high proportion of diatoms in shrimp ponds is desirable (Boyd 1990). By virtue of their high nutritive value, particularly long-chain polyunsaturated fatty acids (PUFAs), many diatom species such as Chaetoceros calcitrans, Skeletonema costatum, Thalasiossira pseudonana, Navicula spp., Nitzschia spp. and Amphora spp. have long been used as live feeds in aquaculture (Brown et al. 1997, Becker 2004, Roy \& Pal 2015).
Phytoplankton stabilize the whole pond ecosystem by minimizing wide fluctuations in water quality and preventing build-up of waste nutrients to toxic levels, thereby ensuring better shrimp growth and yields (Ziemann et al. 1992, Burford 1997, Lemonnier et al. 2017). A positive effect on water quality and productive shrimp performance during the co-culture of 3 species of microalgae and shrimp in a zero-water exchange system was recently demonstrated by Ge et al. (2016). Species succession is often observed in shrimp ponds, starting with some beneficial flagellate and diatom species, followed by unfavourable noxious dinoflagellates after a month of culture (Yusoff et al. 2002, Lemonnier et al. 2016, Lemonnier et al. 2017).

Phytoplankton are extensively grazed by microzooplankton $(20-200 \mu \mathrm{m})$, which form a significant component of the natural biota of shrimp aquaculture ponds (Coman et al. 2003) and are live prey for the cultured shrimps (Calbet \& Landry 2004, Cardozo et al. 2007). Therefore, microzooplankton form an important link between phytoplankton and the shrimps (Rubright et al. 1981). Studies (Tacon et al. 2002, Izquierdo et al. 2006) have shown that shrimps grow best and are healthier in aquaculture systems that have high levels of algae and other natural biota. Owing to their sensitivity to subtle changes such as low dissolved oxygen (DO) levels, high nutrient levels, toxic contaminants, poor food quality and predation occurring in the environment, both phytoplankton and microzooplankton are considered to be good bio-indicators of pond water quality and shrimp health (Casé et al. 2008, Vin 2017). In spite of key roles played by these plankton communities in regulating water quality and in shrimp diet, our knowledge on their composition, abundance, dynamics and succession in shrimp aquaculture ponds is fragmentary (e.g. Burford et al. 2003, Casé et al. 2008, Lemonnier et al. 2016). The majority of previous studies have solely characterized the phytoplankton or the environmental factors, while interrelationships particularly with respect to water quality parameters influencing phytoplankton dynamics and succession - have received limited attention.

Against this background, the present study was undertaken to assess the abundance, composition and succession of phytoplankton and microzooplankton communities and to understand their relationship with water-quality parameters using ecological methods of classification and ordination. We aimed to demonstrate the role of abiotic factors in controlling the abundance and succession of plankton communities and the role of these communities in maintaining water quality in shrimp aquaculture ponds. 


\section{MATERIALS AND METHODS}

\subsection{Culture ponds and farm management}

This study was undertaken in 2 farm ponds located near Kumta town (Karnataka state) on the south-west coast of India $\left(14.42^{\circ} \mathrm{N}, 74.40^{\circ} \mathrm{E}\right)$. The farm is tide-fed from an adjoining creek and is located about $3 \mathrm{~km}$ from the coast. Two ponds (P1 and P2), having an average water depth of $1.2 \mathrm{~m}$ and area of $\sim 0.84$ and $1.06 \mathrm{ha}$, were chosen for the study. Management practices and inputs were similar in P1 and P2. Before stocking, the ponds were sun-dried for $1 \mathrm{mo}$ and limed $\left(\mathrm{CaCO}_{3}\right)$ at a rate of $500 \mathrm{~kg} \mathrm{ha}^{-1}$. The ponds were then filled with dechlorinated seawater, followed by 4 ppm inorganic fertilizer (urea:single super phosphate, 1:1). Organics (wheat bran, yeast and fruit/vegetable juices) were added to enhance the growth of micro- and mesozooplankton and beneficial bacteria. Two weeks after pond preparation, stocking operations were carried out. The summer crop of 2014 with stocking in January and harvesting in April/May was considered for the study.

Healthy post-larvae (PL18) of Litopenaeus vannamei, produced from specific pathogen-free (SPF) broodstock and negative for white spot syndrome virus) as confirmed by PCR, were procured from a nearby commercial shrimp hatchery (Skyline Aqua Hatchery) and transported in oxygen-filled bags to the pond site. The bags were kept in pond water for about $2 \mathrm{~h}$ for acclimation. Actively moving PL18 with no visible signs of disease or morbidity were stocked at a density of 11 and 16 PL18 $\mathrm{m}^{-2}$, respectively, in P1 and P2 during early morning hours. Lime and $\mathrm{pH}$ fixers were added throughout the culture period to buffer $\mathrm{pH}$. The production cycle lasted $96 \mathrm{~d}$ of culture (DoC) with zero water exchange; the required water depth $(\sim 1 \mathrm{~m})$ was maintained by adding fresh dechlorinated water on a fortnightly basis to compensate evaporation and seepage losses. Aeration was achieved using HOBAS aerators (Fernandes et al. 2010). The aeration protocol included $8 \mathrm{~h}$ aeration $\mathrm{d}^{-1}$ up to 50 DoC, $12 \mathrm{~h} \mathrm{~d}^{-1}$ aeration during 51-80 DoC and $16 \mathrm{~h} \mathrm{~d}^{-1}$ aeration thereafter until harvest.

\subsection{Total food consumption, shrimp growth and survival}

Shrimps were fed with commercial shrimp pellets (CP Aquaculture; proximate composition: 38-40\% crude protein; $5 \%$ lipids; $3 \%$ fiber) split across 4 different feed times $(06: 00,11: 00,18: 00$ and 23:00 h) at a rate of $10 \%$ of their body weight during the juvenile stages; feeding was gradually reduced to $2 \%$ towards the end of the culture period. Feeding rates were adjusted according to shrimp biomass and survival. The amount of feed consumed by shrimp in each meal was recorded and calculated as total food consumption per day. Food conversion ratio (FCR) was calculated at the time of harvest (96 DoC) by dividing the total feed consumed on a dry weight basis $(\mathrm{kg})$ by total shrimp production in terms of wet weight $(\mathrm{kg})$. Average growth of shrimp at the time of harvest was calculated by measuring the body weights of 250 shrimps.

\subsection{Water sampling and analysis}

Water samples for analysis of physico-chemical and biological parameters were collected $1 \mathrm{~d}$ prior to the transfer of PL (0 DoC) and thereafter at regular intervals $(12,24,36,48,60,72,84$ and 96 DoC) between January and April 2014 at 3 locations in the middle and edges each pond. A Niskin water sampler was used to collect pond water $(30 \mathrm{~cm}$ above the bottom); sampling time was fixed between 09:00 and 10:00 h. Samples were kept in an icebox and transported to the laboratory for analysis.

Temperature and salinity were measured in situ using a thermometer and a refractometer (Atago), respectively. DO content was estimated by Winkler's method (Parsons et al. 1984). For estimation of dissolved nutrients, including ammonium $\left(\mathrm{NH}_{4}^{+}\right)$, nitrate $\left(\mathrm{NO}_{3}{ }^{-}\right)$, nitrite $\left(\mathrm{NO}_{2}{ }^{-}\right)$and orthophosphate $\left(\mathrm{PO}_{4}{ }^{3-}\right)$, pond water samples $(250 \mathrm{ml})$ were collected in triplicate and preserved in an icebox and transported to the laboratory for analysis. In the laboratory, the water samples were filtered through cellulose filters (pore size: $0.45 \mu \mathrm{m}$ ) using a vacuum pump (Millipore) for removal of unwanted organisms or other suspended particles. Nutrient concentrations were analyzed following Parsons et al. (1984), i.e. ammonium using the salicylate method, nitrate using the cadmium reduction method, nitrite using the diazotization method and orthophosphate by the ascorbic acid method.

\subsection{Plankton sampling and analysis}

Plankton (phytoplankton and microzooplankton) samples were also collected at the time of water sampling. For estimation of chl a concentrations, $500 \mathrm{ml}$ of pond water was filtered through Whatman GF/F glass fiber filter papers $(47 \mathrm{~mm}$ diameter; nominal pore size: $0.7 \mu \mathrm{m})$, extracted in $90 \%$ acetone over- 
night at $5^{\circ} \mathrm{C}$ and the fluorescence measured in a calibrated fluorometer (Turner Designs 10 AU) following Parsons et al. (1984). For estimation of plankton abundance and composition, $500 \mathrm{ml}$ of pond water was filled in a clean polythene bottle and fixed with $1 \%$ Lugol's iodine and $1 \%$ formalin. The samples were allowed to settle in the dark for $48 \mathrm{~h}$ and then were concentrated through $20 \mu \mathrm{m}$ mesh; aliquots were counted in Sedgewick-Rafter cells at 100-400x magnification under a calibrated inverted microscope (Olympus, BH2). Phytoplankton were identified to genus level using keys and illustrations by Subramanyan \& Sarma (1961), Subramanyan (1968), Catalogue of diatoms (1985), Desikachary \& Ranjithadevi (1986), Desikachary \& Prema (1987), Desikachary et al. (1987) and Tomas (1997). Microzooplankton species were identified according to Hada (1938) and Jyothibabu (2004). Species richness $(S)$ was estimated as the total number of species in a given sample. The Shannon-Weiner diversity index $\left(H^{\prime}\right)$ and Pielou's evenness index $(J)$ were used to assess plankton communities according to Shannon \& Weaver (1963) and Pielou (1966), respectively.

\subsection{Statistical analysis}

Temporal and spatial fluctuations in water quality and plankton abundances were assessed by ANOVA (Underwood 1997) with time (DoC) and space (ponds) as sources of variation using the analysis tool pack in Microsoft Excel. Significance in all statistical tests was judged at $p=0.05$. A canonical correspondence analysis (CCA) was used to evaluate the relationship between water quality parameters and groups of phytoplankton and microzooplankton using canonical community ordination (CANOCO) software for Windows v.4.5 (ter Braak \& Šmilauer 2002). Abundance data were square-root transformed and a forward selection procedure of environmental variables was employed. All canonical axes were used to evaluate the significant variables under analysis at the $5 \%$ level by means of a Monte Carlo test (999 random permutations).

\section{RESULTS}

\subsection{Water quality}

ANOVA results for water quality parameters between both ponds are presented in Table 1. Except for higher concentration of DO and lower ammonia and phosphate observed in P2, most of the other parameters were similar between the ponds. Therefore, the results hereafter are combined for both ponds (mean $\pm \mathrm{SD} ; \mathrm{n}=6$; Fig. 1). Water temperature was $28.0 \pm 0.92^{\circ} \mathrm{C}$ at the beginning of culture (0 DoC), had dropped to $26.4 \pm 0.07^{\circ} \mathrm{C}$ by $24 \mathrm{DoC}$ and then increased sharply, reaching $32^{\circ} \mathrm{C}$ on $96 \mathrm{DoC}(\mathrm{p}$ $<0.05)$. Salinity increased significantly from $32 \pm 0.71$ ppt at the beginning to $44 \pm 0.71 \mathrm{ppt}$ at the end of the culture period. Concentrations of DO decreased from $6.8 \pm 1.3(0 \mathrm{DoC})$ to $4.4 \pm 0.9 \mathrm{mg} \mathrm{l}^{-1}$ at $96 \mathrm{DoC}$, with a high value of $8.4 \mathrm{mg} \mathrm{l}^{-1}$ in the middle of the culture period. The concentrations of ammonium and nitrate, respectively, varied from $0.9 \pm 0.07$ to $11 \pm 10 \mu \mathrm{M}$ and from $4 \pm 2.9$ to $104 \pm 94 \mu \mathrm{M}$, both decreasing towards the end of culture (96 DoC), whereas the concentration of phosphate increased from $2.7 \pm 3.6$ (0 DoC) to $10.4 \pm 12 \mu \mathrm{M}$ towards the end of the culture period (96 DoC). The range of $\mathrm{pH}$ was narrow (7-8) and increased towards the end of the culture period.

\subsection{Plankton biomass and abundance}

Chl a concentration ranged from $0.6 \pm 0.07$ to $8.6 \pm$ $3.5 \mathrm{mg} \mathrm{m}^{-3}$ (Fig. 2) and increased as the culture progressed. Phytoplankton cell abundance varied from $1000 \pm 707$ (24 DoC) to $640131 \pm 297083$ cells $^{-1}$ (96 Doc; Fig. 2). Microzooplankton abundance was in the range of $51 \pm 14$ to $145180 \pm 204830$ ind. $1^{-1}$; 3 uniform peaks in abundance were discernible on 24,48 and 84-96 DoC (Fig. 2).

Table 1. ANOVA of water quality parameters between days of culture (DoC) and between the 2 ponds. DO: dissolved oxygen. ${ }^{*} p<0.05$

\begin{tabular}{|lcccccl|}
\hline Parameter & $\begin{array}{l}\text { Source of } \\
\text { variation }\end{array}$ & SS & df & MS & $F$ & $F_{\text {critical }}$ \\
& & & & & \\
\hline Temp. & DoC & 55.2 & 8 & 6.91 & $67.4^{*}$ & 3.44 \\
Salinity & DoC & 231 & 8 & 28.8 & $15.2^{*}$ & 3.44 \\
DO & DoC & 21 & 8 & 2.6 & $14.6^{*}$ & 3.44 \\
Ammonia & DoC & 198 & 8 & 25 & 1.37 & 3.44 \\
Nitrate & DoC & 21699 & 1 & 2712 & 0.09 & 5.32 \\
Phosphate & DoC & 177 & 8 & 22 & 0.98 & 3.44 \\
pH & DoC & 1.62 & 8 & 0.2 & $8.7^{*}$ & 3.44 \\
Chl a & DoC & 166 & 8 & 21 & $7.0^{*}$ & 3.44 \\
Temp. & Pond & 0.18 & 1 & 0.18 & 1.76 & 5.32 \\
Salinity & Pond & 1.4 & 1 & 1.4 & 0.74 & 5.32 \\
DO & Pond & 5.1 & 1 & 5.1 & $29.0^{*}$ & 5.32 \\
Ammonia & Pond & 14.2 & 1 & 14.2 & 0.79 & 5.32 \\
Nitrate & Pond & 193 & 1 & 193 & 0.12 & 5.32 \\
Phosphate & Pond & 208 & 1 & 208 & $9.22^{*}$ & 5.32 \\
pH & Pond & 0.08 & 1 & 0.08 & 3.70 & 5.3 \\
Chl a & Pond & 1.09 & 1 & 1.09 & 0.36 & 5.32 \\
\hline
\end{tabular}



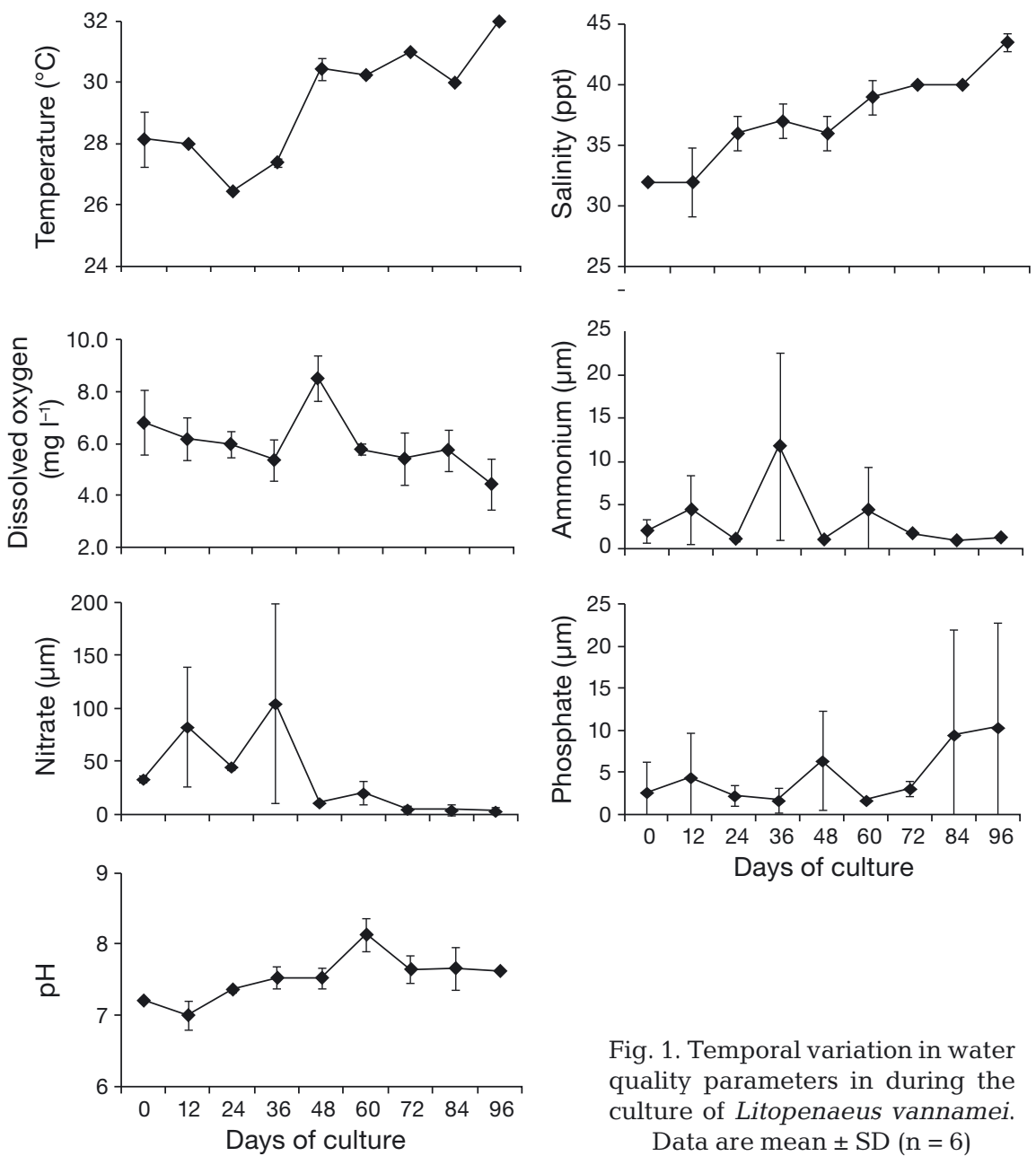

Fig. 1. Temporal variation in water quality parameters in during the culture of Litopenaeus vannamei. Data are mean \pm SD $(n=6)$

riod (Table 2). Of these, only 16 species were centric diatoms. The major contributions to the bulk of the phytoplankton abundance throughout the culture period belonged to Thalassiosira spp., which progressed into a bloom >48 DoC. Leptocylindrus minimum attained an abundance of 3700 cells $1^{-1}$ on 36 DoC, while the abundance of other species of centric diatoms was negligible on all DoC. Compared to the centric diatoms, more species of pennate diatoms (43) were found in the present study. They were mostly from the genera Achnanthes, Navicula, Nitzschia and Pleurosigma. Their numbers were low to moderate on most days, except on 96 DoC where a massive abundance of 165000 cells $\mathrm{l}^{-1}$ of Nitzschia closterium was observed. Thalassionema nitzschioides was also found in moderate abundance (15000 cells l $^{-1}$ ) on 36 DoC.

Microzooplankton comprised 64 species/groups (Table 3). Of these, 14 were heterotrophic dinoflagellates, the majority belonging to Dinophysis sp. and Protoperidinium sp. An unidentified dinoflagellate species with a high abundance of 75000 cells $1^{-1}$ contributed to the microzooplankton abundance peak on 24 DoC (Fig. 2).

\subsection{Frequency of occurrence of plankton communities}

Both centric and the pennate groups of diatoms made up the phytoplankton community structure. Centric diatoms showed almost $100 \%$ frequency of occurrence (\%FO) during 48-84 DoC but decreased sharply to a minimum of $22 \%$ at 96 DoC, with pennate diatoms becoming dominant (Fig. 3a). Overall, the ponds were dominated by centric diatoms. The microzooplankton comprised of ciliates, flagellates, heterotrophic dinoflagellates and larval stages of mesozooplankton (Fig. 3b). Ciliates were dominant on 0, 60 and 72 DoC, heterotrophic dinoflagellates during 1236 DoC and flagellates on 48, 84 and 96 DoC.

\subsection{Plankton community structure}

In total, 59 phytoplankton species comprising mainly diatoms were recorded during the culture pe-
Although as many as 35 species of ciliates were recorded, their abundances were quite low. Moderate abundances of Dadayiella acuta and Tintinnopsis acuta were observed only on 74 DoC and Euplotus balticus, E. crassus and Strombidium caudatum on 96 DoC. Only 2 species of flagellates were recorded, with Eutreptiella marina dominating on 48 and 96 DoC (Fig. 3b) and significantly contributing to the total microzooplankton peaks on those DoC (Fig. 2). Seven mesozooplankton larval/juvenile groups comprising Arachnactis, decapods, naupliar and copepodite stages of copepods, trochophore of polychaetes, invertebrate eggs, foraminifera and ostracods were recorded.

\subsection{Dominant species}

Thalassiosira spp. were the predominant diatoms, contributing over $85 \%$ to phytoplankton abundance (Fig. 4). Of the pennate diatoms, only N. closterium 

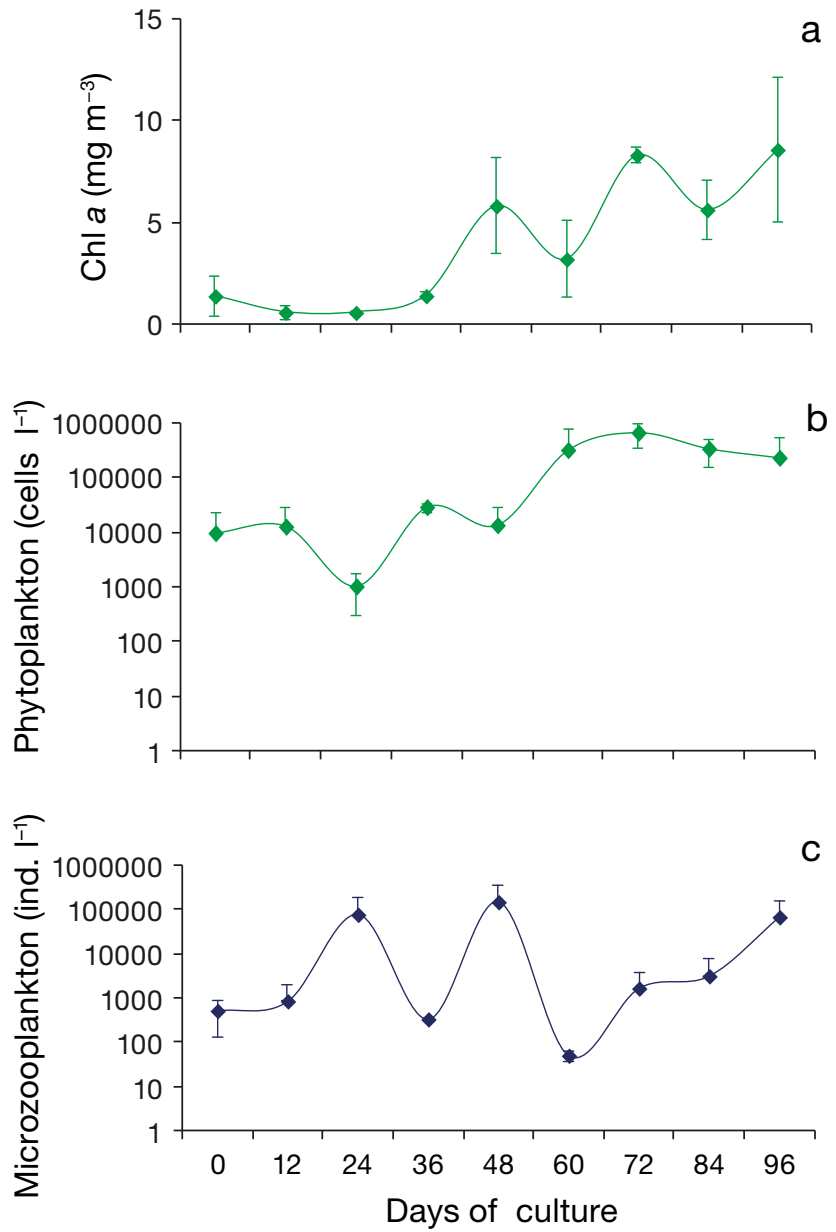

Fig. 2. Temporal variation in (a) concentration of chl $a$ and abundances of (b) phytoplankton and (c) microzooplankton during the culture of Litopenaeus vannamei. Data are mean $\pm \operatorname{SD}(n=6)$

contributed significantly (12.4\%) and Pleurosigma elongatum and T. nitzschioides to a minor extent. Amongst the microzooplankton, the flagellate $E$. marina was the most dominant, contributing $66 \%$ to the abundance. An unidentified species of dinoflagellate (UID2) also contributed significantly (25\%), while a tintinnid, Strombidium caudatum and the copepod nauplii and copepodites were also recorded to a minor extent.

\subsection{Species diversity}

The number of phytoplankton species on various DoC ranged from 6 to 32 (Fig. 5). The maximum number of species was recorded on $12 \mathrm{DoC}$ and the least on 72 and 84 DoC. The diversity of phytoplankton varied from $0.01-1.58$ and was higher on 24,36

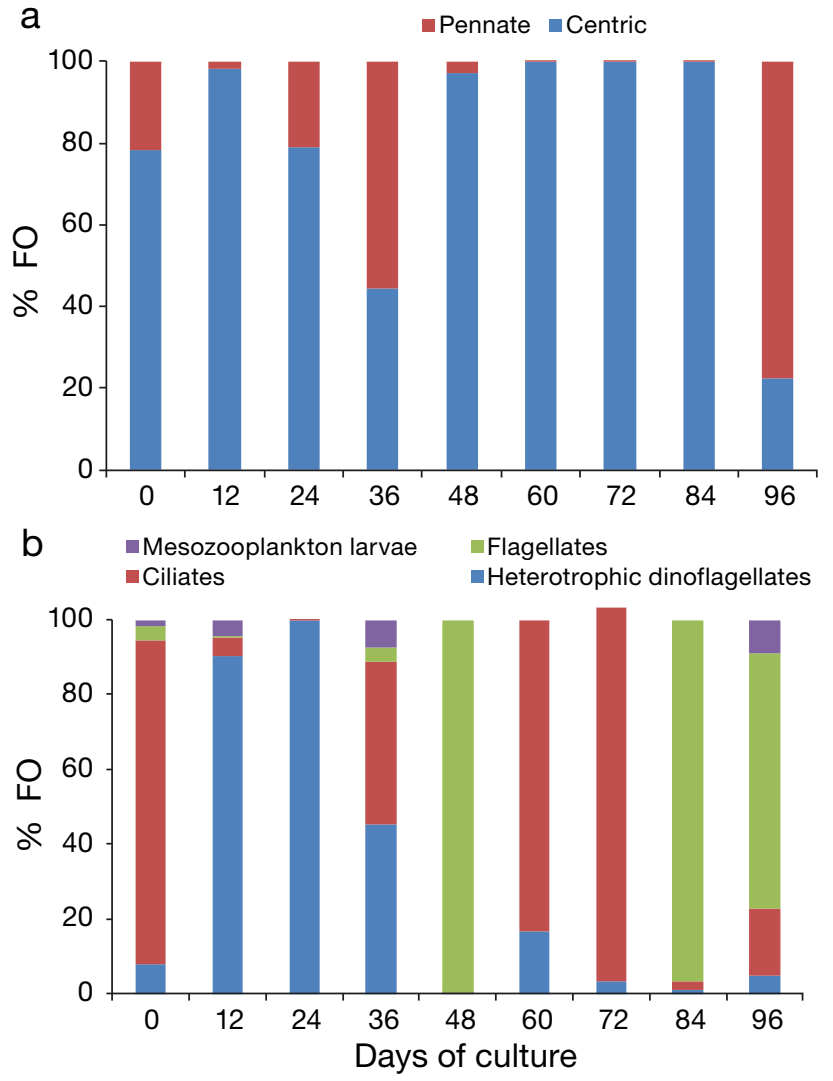

Fig. 3. Frequency of occurrence (\%FO) of (a) diatom and (b) microzooplankton groups during the culture of Litopenaeus vannamei

and 96 DoC. A similar trend was seen in the evenness index, which was quite low and varied from 0.003 to 0.41 . The diversity indices of microzooplankton were quite similar to that of the phytoplankton. The number of species ranged from 3 to 28 , with the highest value on $12 \mathrm{DoC}$ and the lowest on 72 and $84 \mathrm{DoC}$. Diversity of microzooplankton varied from 0.002 to 3.0, with the higher value on 36 DoC corresponding to many species being recorded in very low abundances. Similarly, the lower diversity coincided with the occurrence of high abundance of UID2 (75000 cells $\mathrm{l}^{-1}$ ) on $24 \mathrm{DoC}$ and 145000 ind. $\mathrm{l}^{-1}$ of E. marina on 48 DoC (Table 3). Evenness ranged from 0.01 to 0.89 , with higher values on 36,60 and 72 DoC.

\subsection{CCA}

The effect of water quality on the phytoplankton and microzooplankton communities in P1 and P2 is shown in Fig. 6. Forward selection of water quality parameters retained all the 7-8 variables that significantly explained the species distribution (Table 4). 
Table 2. Temporal variation in abundance $\left(\right.$ cells $\mathrm{l}^{-1}$ ) of phytoplankton communities during the culture of Litopenaeus vannamei in south-western coastal India. -: not present

\begin{tabular}{|c|c|c|c|c|c|c|c|c|c|c|}
\hline \multirow[t]{2}{*}{ Code } & \multirow[t]{2}{*}{ Species } & \multicolumn{9}{|c|}{ Days of culture } \\
\hline & & 0 & 12 & 24 & 36 & 48 & 60 & 72 & 84 & 96 \\
\hline & Centric diatoms & & & & & & & & & \\
\hline DC1 & Arcocellulus cornucervis & - & - & 2 & - & - & - & - & - & - \\
\hline DC2 & Cerataulina pelagica & 67 & 4 & - & 33 & - & - & - & - & - \\
\hline DC3 & Corethron criophilum & - & 4 & - & - & - & - & - & - & - \\
\hline DC4 & Cyclotella ocula & - & - & - & 13 & - & - & - & - & - \\
\hline DC5 & Cymatocira belgica & - & - & 2 & - & - & - & - & - & - \\
\hline DC6 & Dactyliosolen fragilissimus & - & 4 & - & 13 & - & - & - & - & - \\
\hline DC7 & Eucampia groenlandica & - & 4 & - & - & - & - & - & - & - \\
\hline DC8 & Eucampia zoodiacus & - & 4 & - & - & - & - & - & - & - \\
\hline DC9 & Guinardia delicatula & - & 8 & - & - & - & - & - & - & - \\
\hline DC10 & Guinardia striata & - & 2 & - & - & - & - & - & - & - \\
\hline DC11 & Leptocylindrus danicus & - & 7 & - & - & - & - & - & - & - \\
\hline DC12 & Leptocylindrus minimum & - & 7 & 3 & 3700 & - & - & - & - & - \\
\hline DC13 & Odontella longicornis & - & 4 & - & - & - & - & - & - & - \\
\hline DC14 & Rhizosolenia hyalina & _- & 4 & - & _- & _- & - & _- & - & - \\
\hline DC15 & Thalassiosira sp. & 7300 & 12064 & 202 & 8673 & 1057 & 307565 & 125000 & 76 & 50010 \\
\hline DC16 & Thalassiosira sp. 1 & - & - & - & - & 11667 & - & 515000 & 100250 & - \\
\hline & Pennate diatoms & & & & & & & & & \\
\hline DP17 & Achnanthes delicatula & - & - & - & - & - & - & 50 & - & - \\
\hline DP18 & Achnanthes exigua & - & 0.2 & - & - & - & - & - & - & - \\
\hline DP19 & Achnanthes frigidus & - & - & - & 33 & 10 & - & - & - & - \\
\hline DP20 & Achnanthes longipes & - & 49 & - & - & - & - & - & - & - \\
\hline DP21 & Amphora sp. & - & - & - & - & - & - & 50 & - & - \\
\hline DP22 & Amphiprora alata & - & 4 & - & - & - & - & - & - & - \\
\hline DP23 & Amphiprora paludosa & - & - & - & 33 & - & - & - & - & - \\
\hline DP24 & Cylindrotheca closterium & - & - & - & - & - & - & - & - & 360 \\
\hline DP25 & Cymbella marina & - & - & - & - & - & - & - & - & - \\
\hline DP26 & Diploneis suborbicularis & - & 7 & - & 25 & 20 & - & - & - & - \\
\hline DP27 & Epithemia adnata & - & - & - & - & 120 & - & - & - & - \\
\hline DP28 & Fragilaria ulna & - & - & - & - & - & - & - & - & 15 \\
\hline DP29 & Haslea trompii & - & 2 & - & - & - & - & - & - & 30 \\
\hline DP30 & Licmophora abbreviata & - & - & - & - & - & - & - & - & 1530 \\
\hline DP31 & Licmophora flabellata & - & 2 & 0.3 & - & - & - & - & - & - \\
\hline DP32 & Navicla subminiscula & 8 & - & - & - & - & - & - & - & - \\
\hline DP33 & Navicla transitrans & - & - & - & - & - & 20 & - & 25 & - \\
\hline DP34 & Navicula sp. & 0.4 & - & 2 & - & - & 5 & - & - & 60 \\
\hline DP35 & Navicula sp.1 & - & 2 & - & - & - & - & - & - & - \\
\hline DP36 & Nitzschia closterium & 4 & - & - & 12 & - & - & - & - & 165000 \\
\hline DP37 & Nitzschia dissipata & - & 13 & - & - & - & - & - & - & - \\
\hline DP38 & Nitzschia longissima & - & - & 2 & - & - & 30 & - & - & - \\
\hline DP39 & Nitzschia sicula & 8 & - & - & 45 & - & - & - & - & 1500 \\
\hline DP40 & Nitzschia sigma & - & 7 & - & - & 4 & 35 & - & - & 1500 \\
\hline DP41 & Nitzschia sp. & - & 4 & - & - & - & - & - & - & - \\
\hline DP42 & Phaeodactylum tricornutum & - & - & - & - & - & 5 & - & - & - \\
\hline DP43 & Plagiotropis gausii & - & - & - & - & - & - & - & - & 30 \\
\hline DP44 & Pleurosigma angulatum & - & 7 & - & - & - & - & - & - & - \\
\hline DP45 & Pleurosigma capense & 8 & 18 & - & _- & 26 & - & _- & - & - \\
\hline DP46 & Pleurosigma elongatum & 1967 & 9 & 50 & 386 & 85 & 75 & 1 & 101 & 2325 \\
\hline DP47 & Pleurosigma directum & - & 52 & - & 25 & 30 & 5 & - & - & - \\
\hline DP48 & Pleurosigma normanii & 8 & - & - & - & - & - & - & - & - \\
\hline DP49 & Pleurosigma sp. & 8 & 8 & - & - & - & - & - & - & - \\
\hline DP50 & Pleurosigma sp.1 & 25 & 8 & - & - & - & - & - & - & - \\
\hline DP51 & Pleurosigma sp. 2 & - & 2 & - & - & - & - & - & 75 & - \\
\hline DP52 & Pseudonitzschia delicatissima & - & - & 0.3 & - & - & - & - & - & - \\
\hline DP53 & Rhopalodia gibberula & - & - & 2 & - & - & - & - & - & - \\
\hline DP54 & Stauroneis constricta & - & 4 & - & - & - & - & - & - & - \\
\hline DP55 & Synedra formosa & - & - & - & - & - & - & - & - & 15 \\
\hline DP56 & Synedra ulna & - & 9 & - & - & 60 & 5 & - & - & 30 \\
\hline DP57 & Thalassionema nitzschioides & - & - & - & 15000 & - & - & 30 & - & - \\
\hline DP58 & Toxarium undulatum & - & - & - & - & 10 & - & - & - & - \\
\hline DP59 & Unidentified species & - & - & - & 13 & - & - & - & - & - \\
\hline Total & Centric diatoms & 7367 & 12112 & 209 & 12431 & 12723 & 307565 & & 100326 & 50010 \\
\hline & Pennate diatoms & 2038 & 204 & 56 & 15572 & 375 & 180 & 131 & 201 & 172395 \\
\hline
\end{tabular}


Table 3. Temporal variation in abundance (ind. $\mathrm{l}^{-1}$ ) of microzooplankton communities during the culture of Litopenaeus vannamei in south-western coastal India. -: not present

\begin{tabular}{|c|c|c|c|c|c|c|c|c|c|c|}
\hline \multirow[t]{2}{*}{ Code } & \multirow[t]{2}{*}{ Species } & \multicolumn{9}{|c|}{ - Days of culture } \\
\hline & & 0 & 12 & 24 & 36 & 48 & 60 & 72 & 84 & 96 \\
\hline & Heterotrophic dinoflagellates & & & & & & & & & \\
\hline Hd1 & Ceratium dens & 0.2 & 4 & - & - & - & - & - & - & - \\
\hline $\mathrm{Hd} 2$ & Dinophysis acuminata & - & - & - & - & - & - & - & - & 1500 \\
\hline $\mathrm{Hd} 3$ & Dinophysis acuta & 40 & - & - & - & - & - & - & - & 1500 \\
\hline $\mathrm{Hd} 4$ & Dinophysis sp. & - & - & - & 25 & - & - & - & - & - \\
\hline Hd5 & Ornithocercus steinii & - & - & 0.3 & 100 & - & - & - & - & - \\
\hline Hd6 & Protoperidinium brevipes & - & 733 & - & - & - & - & - & - & 15 \\
\hline $\mathrm{Hd} 7$ & Protoperidinium conicoides & - & - & - & - & - & - & - & - & 60 \\
\hline Hd8 & Protoperidinium conicum & - & 20 & - & - & - & - & - & - & - \\
\hline Hd9 & Protoperidinium pellucidum & - & - & - & - & - & - & - & 25 & - \\
\hline Hd10 & Prorocentrum minimum & - & - & 2 & - & - & - & - & - & - \\
\hline Hd11 & Pyrocystis lunula & - & - & 2 & - & 2 & 10 & - & - & - \\
\hline $\operatorname{Hd} 12$ & Zygabikodinium lenticulatum & - & - & - & - & 8 & - & - & - & - \\
\hline Hd13 & Unidentified dinoflagellate1 & - & 3 & - & 25 & - & - & - & - & - \\
\hline Hd14 & Unidentified dinoflagellate2 & - & - & 75000 & - & - & - & - & - & - \\
\hline \multirow[t]{2}{*}{ Hd15 } & Dinoflagellate cysts & - & - & - & - & - & - & 50 & - & - \\
\hline & Ciliates & & & & & & & & & \\
\hline $\mathrm{C} 16$ & Acineta sp. & - & - & - & 13 & - & - & - & - & - \\
\hline $\mathrm{C} 17$ & Acanthostomella norveigica & - & - & - & 13 & - & - & - & - & - \\
\hline $\mathrm{C} 18$ & Actinosphaerium sp. & - & 4 & - & - & 150 & - & - & - & - \\
\hline C19 & Amphorides minor & - & 0.3 & - & - & - & - & - & - & - \\
\hline $\mathrm{C} 20$ & Dadayiella acuta & - & - & - & - & - & - & 1000 & - & - \\
\hline $\mathrm{C} 21$ & Epiplocycloides reticulata & - & 4 & - & - & - & - & - & - & - \\
\hline $\mathrm{C} 22$ & Euplotes balticus & - & - & - & - & - & - & - & - & 1500 \\
\hline $\mathrm{C} 23$ & Euplotes crassus & - & - & - & - & - & - & - & - & 1500 \\
\hline $\mathrm{C} 24$ & Eschaneustyla sp. & - & 4 & - & - & - & 5 & - & - & - \\
\hline $\mathrm{C} 25$ & Eutintinnus elongatus & 120 & 0.3 & - & - & - & - & - & - & 15 \\
\hline $\mathrm{C} 26$ & Favella ehrenbergii & - & 2 & - & - & - & - & - & - & - \\
\hline $\mathrm{C} 27$ & Favella turaikaensis & 20 & - & - & - & - & - & - & - & - \\
\hline $\mathrm{C} 28$ & Favella sp. & 20 & - & - & - & - & - & - & - & - \\
\hline $\mathrm{C} 29$ & Keronopsis sp. & - & - & - & - & - & 30 & - & - & - \\
\hline C30 & Laboea strobila & 280 & - & - & 13 & - & - & - & - & - \\
\hline C31 & Myrionecta rubra & - & 4 & - & 25 & 10 & - & - & - & - \\
\hline C32 & Rhabdonella poculum & - & 2 & - & - & - & - & - & - & - \\
\hline C33 & Rhabdonella amor & - & 2 & - & - & - & - & - & - & - \\
\hline C34 & Rhabdonella spiralis & - & 0.3 & 3 & - & - & - & - & - & - \\
\hline C35 & Salpingacantha ampla & - & 2 & - & - & - & - & - & - & - \\
\hline $\mathrm{C} 36$ & Salpingella decurtata & - & 8 & - & - & - & - & - & - & - \\
\hline C37 & Spirostomum sp. & - & - & - & 33 & - & - & - & - & - \\
\hline C38 & Strombidium conicum & - & 0.01 & - & - & - & - & - & - & - \\
\hline C39 & Strombilidium strobilus & 0.2 & - & - & - & - & - & - & - & - \\
\hline $\mathrm{C} 40$ & Strombilidium reticulatum & 4 & - & - & - & - & - & - & - & - \\
\hline C41 & Strombilidium turicum & - & - & - & - & - & - & - & - & - \\
\hline $\mathrm{C} 42$ & Salpingacantha sp. & - & 7 & - & - & - & - & - & 75 & - \\
\hline $\mathrm{C} 43$ & Strombidium caudatum & - & - & - & 15 & - & - & - & - & 9000 \\
\hline $\mathrm{C} 44$ & Strombidium cornucopiae & - & - & - & - & - & 5 & - & - & - \\
\hline $\mathrm{C} 45$ & Tintinnopsis entzil & - & - & - & - & - & 10 & - & - & - \\
\hline $\mathrm{C} 46$ & Tinntinnopsis aperta & - & 2 & - & - & - & - & - & - & - \\
\hline $\mathrm{C} 47$ & Tinntinnopsis fusus & - & - & - & 33 & - & - & - & - & - \\
\hline $\mathrm{C} 48$ & Tinntinnopsis minuta & - & - & - & - & - & - & 500 & - & - \\
\hline $\mathrm{C} 49$ & Trichocerca rousseleti & - & 4 & - & - & - & - & - & - & - \\
\hline \multirow[t]{2}{*}{ C50 } & Unidentified & - & - & - & - & - & - & 90 & - & - \\
\hline & Flagellates & & & & & & & & & \\
\hline F51 & Campanoeca dilatata & - & 2 & - & - & - & - & - & - & - \\
\hline F52 & Eutreptiella marina & 20 & - & - & 13 & 145000 & - & - & 3000 & 45150 \\
\hline
\end{tabular}


Table 3 (continued)

\begin{tabular}{|c|c|c|c|c|c|c|c|c|c|c|}
\hline \multirow[t]{2}{*}{ Code } & \multirow[t]{2}{*}{ Species } & \multicolumn{9}{|c|}{ - Days of culture } \\
\hline & & 0 & 12 & 24 & 36 & 48 & 60 & 72 & 84 & 96 \\
\hline & Mesozooplankton larvae & & & & & & & & & \\
\hline M53 & Arachnachtis larvae & - & 3.5 & - & - & - & - & - & - & - \\
\hline M54 & Decapod larva & 0.2 & - & - & - & - & - & - & - & - \\
\hline M55 & Foraminifera & 0.2 & - & - & - & - & - & - & - & - \\
\hline M56 & Invertebrate egg & 1.2 & - & - & - & - & - & - & - & - \\
\hline M57 & Nauplii and copepodites & 4.8 & 27.8 & - & 11.7 & - & - & - & - & 6000 \\
\hline M58 & Ostracod & - & - & - & 12.5 & - & - & - & - & - \\
\hline M59 & Polychaete trocophore & 2.0 & 6.7 & - & - & - & - & - & - & - \\
\hline \multirow[t]{4}{*}{ Total } & Dinoflagellates & 40 & 760 & 75004 & 150 & 10 & 10 & 50 & 25 & 3075 \\
\hline & Ciliates & 444 & 43 & 3 & 144 & 160 & 50 & 1590 & 75 & 12016 \\
\hline & Flagellates & 20 & 2 & 0 & 13 & 145000 & 0 & 0 & 3000 & 45150 \\
\hline & Mesozooplankton larvae & 8 & 38 & 0 & 24 & 0 & 0 & 0 & 0 & 6000 \\
\hline
\end{tabular}

a

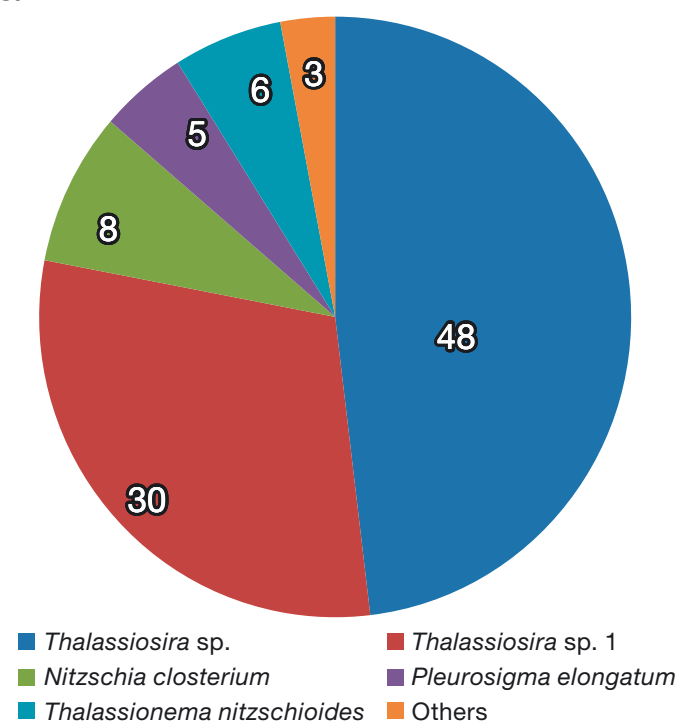

b

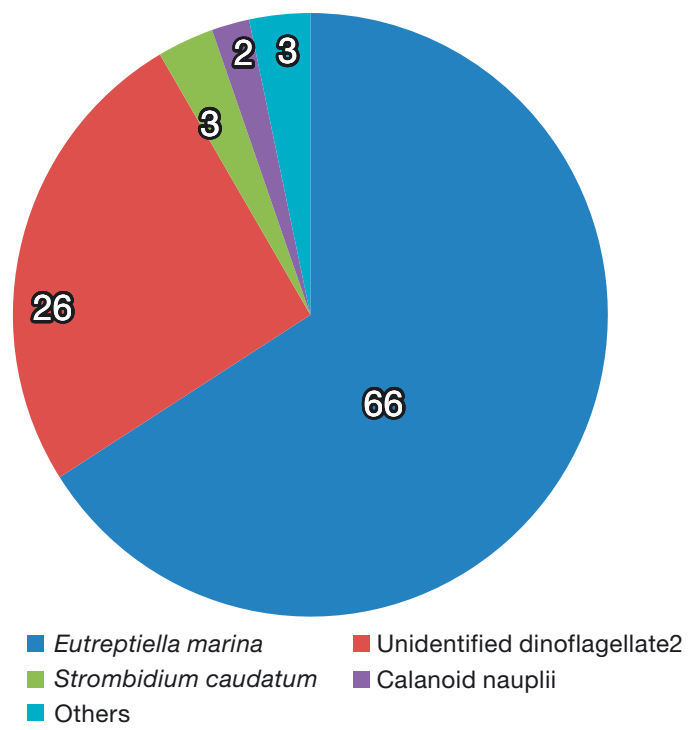

Fig. 4. Relative percent contribution of (a) phytoplankton and (b) microzooplankton species during the culture of Litopenaeus vannamei

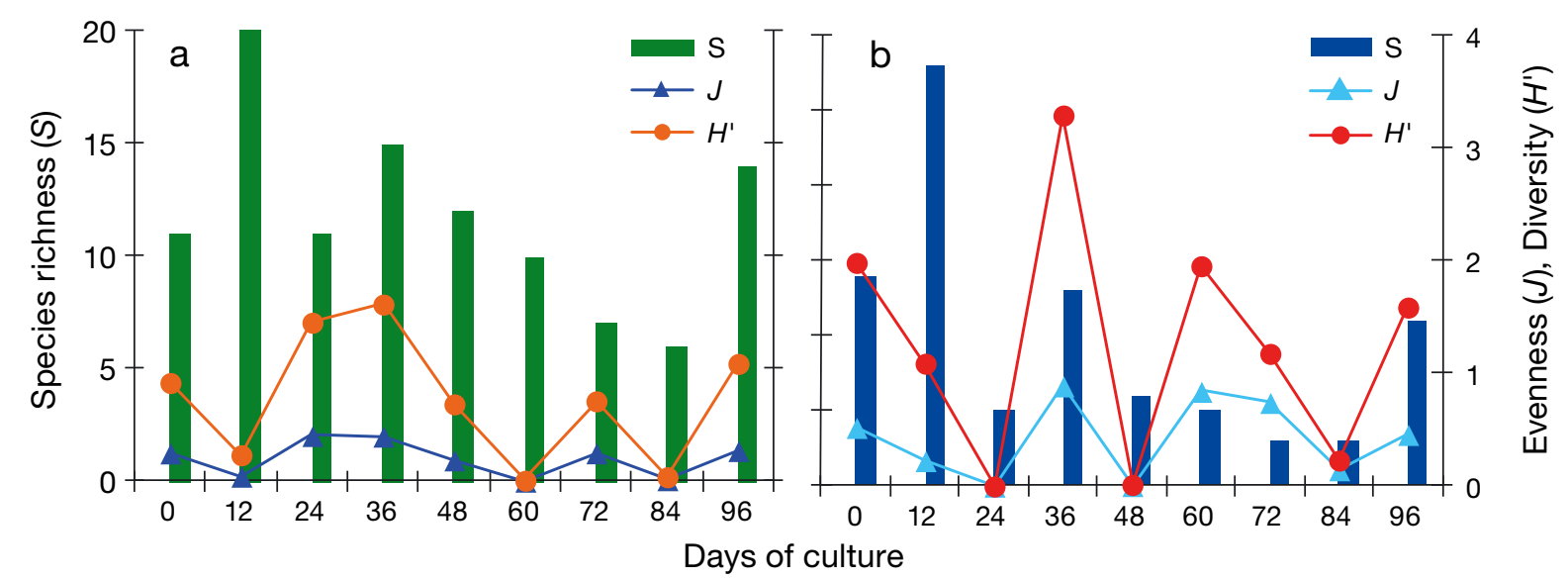

Fig. 5. Temporal variation in species diversity indices of (a) phytoplankton and (b) microzooplankton during the culture of Litopenaeus vannamei 
a) Centric diatoms

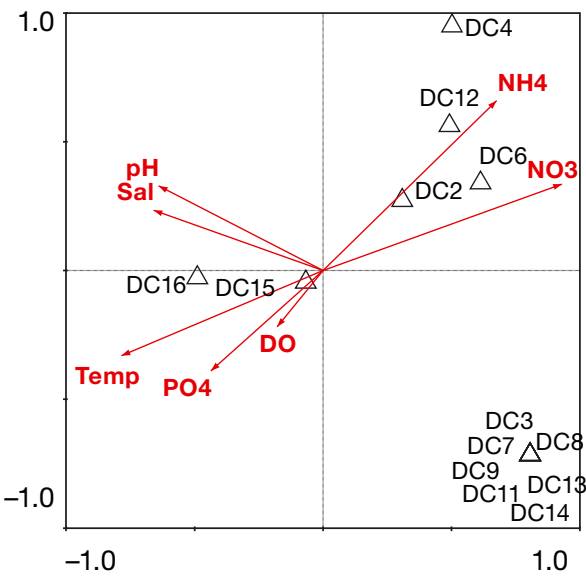

c) Heterotrophic dinoflagellates b) Pennate diatoms

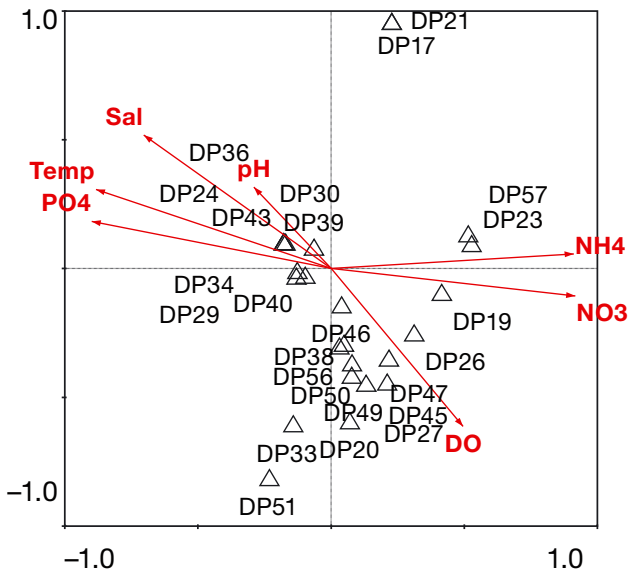

d) Ciliates, flagellates, nauplii and copepodites

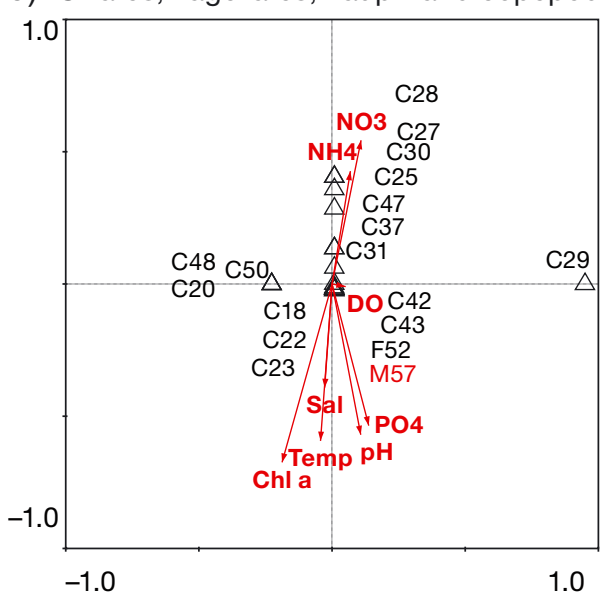

Fig. 6. Canonical correspondence analysis ordination diagram of water quality parameters with species/genus/groups of (a,b) phytoplankton and (c,d) microzooplankton during the culture of Litopenaeus vannamei. Results are for axis 1 (horizontal) and axis 2 (vertical); arrows represent forward-selected water quality variables (Temp: temperature; Sal: salinity; $\mathrm{NH}_{4}$ : ammonium; $\mathrm{NO}_{3}$ : nitrate; $\mathrm{PO}_{4}$, phosphate; Chl a: chlorophyll $a_{i}$ DO: dissolved oxygen). Arrow length indicates the strength of that variable in explaining the species distribution during the culture; arrow direction: approximate correlation to the ordination axes.

For groups/species codes, refer to Tables $2 \& 3$

Table 4. Summary for the 2 axes (Ax1 and Ax2) of canonical correspondence analysis with 8 selected environmental factors. $\%$ var sp-env: cumulative percentage variance of species-environment relation; eigenvalues: sum of eigenvalues and canonical eigenvalues; Cil-fla-na-co: ciliates, flagellates, nauplii and copepodites

\begin{tabular}{|c|c|c|c|c|c|c|c|c|}
\hline \multirow[t]{2}{*}{ Variable } & \multicolumn{2}{|c|}{ Centric diatoms } & \multicolumn{2}{|c|}{ Pennate diatoms } & \multicolumn{2}{|c|}{ Dinoflagellates } & \multicolumn{2}{|c|}{ Cil-fla-na-co } \\
\hline & $\mathrm{Ax} 1$ & $\mathrm{Ax} 2$ & Ax1 & $\mathrm{Ax} 2$ & $\mathrm{Ax} 1$ & $\mathrm{Ax} 2$ & Ax1 & $\mathrm{Ax} 2$ \\
\hline Temperature & -0.77 & -0.33 & -0.88 & 0.31 & 0.18 & 0.86 & -0.04 & -0.59 \\
\hline Salinity & -0.65 & 0.23 & -0.70 & 0.52 & 0.10 & 0.56 & -0.03 & -0.39 \\
\hline Dissolved oxygen & 0.18 & -0.22 & 0.49 & -0.61 & -0.04 & -0.73 & 0.05 & -0.01 \\
\hline Ammonium & 0.66 & 0.65 & 0.90 & 0.06 & 0.01 & 0.39 & 0.07 & 0.43 \\
\hline Nitrate & 0.91 & 0.33 & 0.91 & -0.11 & -0.20 & 0.50 & 0.11 & 0.54 \\
\hline Phosphate & -0.43 & -0.38 & -0.89 & 0.18 & -0.03 & 0.85 & 0.14 & -0.53 \\
\hline $\mathrm{pH}$ & -0.63 & 0.32 & -0.29 & 0.32 & 0.21 & 0.30 & 0.10 & -0.57 \\
\hline Chl a & & & & & 0.23 & 0.78 & -0.18 & -0.67 \\
\hline Eigenvalues & 0.57 & 0.34 & 0.77 & 0.65 & 1.00 & 0.99 & 1.00 & -0.72 \\
\hline$\%$ var sp-env & 51.3 & 82.5 & 27.2 & 50.1 & 22.0 & 43.8 & 26.7 & 46.0 \\
\hline Total inertia & & 1.34 & & 3.34 & & 4.56 & & 3.74 \\
\hline Sum eigenvalues & & 1.34 & & 3.34 & & 4.56 & & 3.74 \\
\hline Sum canonical eigenvalues & & 1.10 & & 2.85 & & 4.56 & & 3.74 \\
\hline
\end{tabular}


In the biplot for centric diatom species (Fig. 6a), the first 2 axes (Ax1 and Ax2) explained $83 \%$ of the total variance of species-environmental data. Ax1 and Ax2 respectively explained 51 and $31 \%$ of the total variance. All canonical axes were significant $(\mathrm{p}<$ 0.05). Ax1 separated species found in a higher nitrate and ammonium environment from species corresponding to periods of higher temperature, salinity and $\mathrm{pH}$. Following $\mathrm{Ax} 1$, the species Ceratualina pelagica, Cyclotella ocular, Dactyliosolen fragilissimus and L. minimum were found in high nitrate and ammonium conditions, whereas the increase in abundances of Thalassiosira spp. correlated with elevated temperature, salinity and $\mathrm{pH}$.

In the biplot for pennate diatoms (Fig. 6b), Ax1 and Ax2 explained $50 \%$ of the total variance. Ax1 positively correlated with ammonium and nitrate, and the species placed along this axis were Achnanthes frigidus, Amphiprora paludosa, Diploneis suborbicularis and T. nitzschioides. The same axis negatively correlated with phosphate, temperature and salinity, and the species Cylindrotheca closterium, Haslea trompii, Licmophora abbreviata, Navicula sp., $N$. closterium, Nitzschia sicula, Plagiotropis gausii and Nitzschia sigma were associated with it. Along the negative side of Ax2 was the factor DO, which showed good correlation with Epithemia adnata, Navicula transitrans, Nitzschia longissima, Pleurosigma capense, P. elongatum, P. directum, Pleurosigma spp. and Synedra ulna.

In the biplot for dinoflagellates (Fig. 6c), Ax1 and Ax2 explained $44 \%$ of the total variance. Most of the dinoflagellates were loaded along Ax2 at higher temperature and salinity and higher concentrations of phosphate and chl $a$. On the other side of the same axis were DO and nitrate, which correlated with most dinoflagellates except an unidentified species.

In the biplot for ciliates, flagellates and copepod nauplii and copepodites (Fig. 6d), Ax1 and Ax2 explained $46 \%$ of the total variance. Most of the species were separated along Ax2. Along the positive side of this axis, species such as Eutintinnus elongatus, Favella turaikaensis, Favella sp., Laboea strobila, Myrionecta rubra, Spirostomum sp. and Tinntinnopsis fusus correlated with nitrate and ammonium. Along the center of Ax2 were the species Actinosphaerium sp., E. balticus, E. crassus, Eutreptiella marina, Salpingacantha sp., Strombidium caudatum and copepod nauplii and copepodites, indicating that they were influenced by factors on both sides of the axis including nitrate, ammonium, temperature, $\mathrm{pH}$, chl $a$ and phosphate.

\subsection{Growth, survival and production of shrimp}

Mean \pm SE shrimp production after 96 DoC was $0.23 \pm 0.07 \mathrm{~kg} \mathrm{~m}^{-2}$ and the final weight gain was $20.6 \pm 0.3 \mathrm{~g} \mathrm{shrimp}^{-1}$. The survival rate was $83 \pm 6.4 \%$ and the FCR was $1.56 \pm 0.14$.

\section{DISCUSSION}

In spite of differences in stocking densities between P1 and P2, the variations in major water quality parameters were similar in both ponds during the shrimp growth cycle. This may, primarily, be attributable to the common source of the inlet water and, secondarily, by good pond management practices. Being at the base of the food chain, autotrophic phytoplankton serve as a direct food source for the PL of penaeid shrimps (Coutteau 1996). Diatoms contain an average of $32-38 \%$ crude protein (Gordon et al. 2006), which is the major component of the natural food of penaeid shrimps. By contributing to DO, uptake of nutrients and supporting zooplankton grazers, phytoplankton play a pivotal role in maintaining water quality, which is critical for sustainable shrimp production (Mohanty et al. 2018). Phytoplankton abundance varied widely, from 10 to $10^{5}$ cells $\mathrm{l}^{-1}$, increasing significantly towards the end of the culture period. Among the many factors that affect phytoplankton growth and abundance, light intensity, nutrients and zooplankton grazing are important (Chien 1992). Solar irradiance is not a limiting factor in the present study, as the ponds are situated in a tropical marine region.

The influence of water temperature on the survival, growth, oxygen solubility and consumption and immune response of cultured shrimp has been documented (Guan et al. 2003, Abdelrahman et al. 2019). The initial temperature and salinity in the ponds are dependent on the inlet water and changes are driven by climatic conditions (Welch 1952). During the summer production cycle of shrimp, with stocking in January and the harvest in April, a seasonal warming along with the progress of the culture was observed. The temperature range $\left(26-32^{\circ} \mathrm{C}\right)$ recorded during the present study has been reported to be optimal for the growth of Litopenaeus vannamei (Nuñez-Pastén 1988). The increase in salinity towards the end of the culture period was related to increased evaporation during the warmer months. In general, shrimps are euryhaline species and $L$. vannamei can easily adapt to varying levels of salinity (Ponce-Palafox et al. 1997). 
Diatoms emerged as the major group in both ponds during 96 DoC. This is primarily because of their presence in the source water taken from the estuarine region off the west coast of India which is rich in diatoms (Pednekar et al. 2014). The high nitrate concentration, which ranged from 4-105 $\mu \mathrm{M}$ in the ponds, is favorable for the growth of diatoms (Malone 1980). The dominance of particular algal groups in aquaculture ponds is affected by abiotic and biotic factors such as salinity (Chien 1992), light (Burford 1997), pond-flushing (Tseng et al. 1991), organic enrichment (Lemonnier et al. 2017) and nutrient concentrations and their ratios (Boyd 1995, Paerl \& Tucker 1995). Diatoms require a wide variety of inorganic nutrients for growth, but the most important are nitrogen and phosphorus (Dawes 1981). The requirement for silica for the growth of diatom shells is mostly derived from shrimp pond sediments (Cremen et al. 2007).

Higher amounts of nutrients and metabolic wastes enter the water as the daily feed allotment increases in response to shrimp biomass increase during the progression of the culture. It has been reported that as much as $80 \%$ of the nitrogen from the shrimp feed accumulates in the water as excess (Sanders et al. 1987). Ammonia is formed during protein catabolism in shrimps and can account for 40-90\% of nitrogen excretion (Parry 1960). Nitrate is a product of nitrification in pond water and is dependent on the addition of fertilizers and feed. Remineralization of nitrogen from feed and from shrimp excreta might have led to a gradual increase in the availability of nitrate and ammonium-nitrogen $\left(\mathrm{NH}_{4}{ }^{+}-\mathrm{N}\right)$ in the ponds up to $36 \mathrm{DoC}_{i}$ however, the concentrations of ammonium recorded during this study $(1-11 \mu \mathrm{M})$ were within the optimum range for the growth and survival of penaeid shrimps (Chien 1992). Higher concentrations of unionized ammonia $\left(\mathrm{NH}_{3}{ }^{-}\right)$have been reported to cause stress to cultured shrimps (Burford \& Lorenzen 2004); however, the maintenance of optimum $\mathrm{pH}(7-8)$ in the ponds helped in regulating the ammonium levels, thereby keeping its unionized form under control. A dramatic decrease in the concentrations of nitrate and ammonium after 36 DoC and an increase in phytoplankton abundance until 96 DoC were observed (Fig. 2). As nitrate and ammonium are essential nutrients that encourage the growth of phytoplankton (Shan \& Obbard 2001), the lower levels of these nutrients recorded after 36 DoC were possibly due to their uptake by phytoplankton. Thus, uptake by phytoplankton, as well as adequate aeration and addition of probiotics, may have prevented the build-up of ammonia to toxic levels
(Martinez-Cordova et al. 1998, Lorenzen 1999, Fernandes et al. 2010).

Higher concentrations of chl a observed towards the end of the production cycle may have been due to the significant increase in phytoplankton abundance, mainly by 2 co-dominant species of the centric diatoms Thalassiosira sp., reaching nearly bloom proportions. Such an increase in abundance of plankton over the culture period has been reported previously in shrimp cultures (e.g. Alonso-Rodriguez \& PáezOsuna 2003). Since the bloom was composed of multi-species of Thalassiosira sp. as well as pennate diatoms such as Nitzschia closterium, Pleurosigma elongatum and Thalassionema nitzschioides in moderate numbers, similar to observations of Smith (1985), the bloom persisted from the middle to the end of the culture period. Thalassiosira spp. is a nanoplanktonic diatom that grows rapidly when nutrients are increased; it has been reported as a major component of the spring diatom bloom in shallow euphotic zones of many coastal waters (Guillard \& Kilham 1977, Waite et al. 2005) and also a significant proportion of phytoplankton community in densely stocked shrimp ponds (Melo et al. 2010, Lemonnier et al. 2016). By virtue of their importance in substantially contributing to the growth performance of L. vannamei even at adult stages (Moss 1994) and provision of adequate levels of the dietary requirements of PUFAs, eicosapentaenoic acid and/or docosahexaenoic acid and arachidonic acid (Volkman et al. 2006), these centric diatom species are highly desirable in shrimp ponds.

As also reported by Yusoff et al. (2002) and Lemonnier et al. (2017), phytoplankton blooms occur in response to increased amounts of nutrients from the metabolic wastes of shrimp. Smith (1983) suggested that in tropical areas where the temperature is high and light is abundant, phytoplankton blooming could be due to the rapidly changing nutrient concentration and nitrogen:phosphorus ratios. The most favorable nitrogen:phosphorus ratio for blooming diatoms in shrimp ponds has been reported to be 20:1 (Daniels \& Boyd 1993). Ratios of nitrogen:phosphorus during 96 DoC varied from 0.3-61, with higher values during 0-36 DoC and then decreasing to $<12$ with further progression of the culture. Such a decrease in the nitrogen:phosphorus ratio might be related to the accumulation of phosphate towards the end of the production cycle. The build-up of phosphorus might have stimulated the peaking of diatom production (Fig. 2) in the presence of adequate nitrogen towards the end of culture, as has also been observed by Stickney (2005) and Castillo-Soriano et 
al. (2013). Interestingly, few studies have reported a dominance of cyanophytes coupled with a high phosphate concentration (Yusoff et al. 2002, Shaari et al. 2011). Silicate:nitrogen ratios affecting diatom dominance has been reported by Sommer (1989). Though silicate was not measured in this study, we assumed from a similar study (Smith 1994) that amorphous silica present in the shrimp pond sediments was adequate enough in promoting diatom growth and apparently depressed the growth of cyanophytes.

With an increase in phosphorus loading, a shift in communities from diatoms to dinoflagellates has been observed by Hodgkiss (2001). In our study, few heterotrophic dinoflagellates belonging to the genera Dinophysis and Protoperidinium were recorded intermittently during the production cycle. Additionally, the occurrence of UID2 in high abundance $\left(>10^{5}\right.$ cells $\mathrm{l}^{-1}$ ) at 24 DoC was recorded. However, none of these dinoflagellate species belonged to the harmful category. Leaching of humic acids and other organic substances from feed is known to stimulate the growth of dinoflagellates (Prakash \& Rashid 1968). The occurrence of Protoperidinium spp. is common along the west coast of India (e.g. D'Silva et al. 2011). These non-pigmented, phagotrophic dinoflagellates often occur in high abundance during diatom blooms and are significant consumers of blooming diatoms (Sherr \& Sherr 2007). In the present study, the lower abundance of Thalassiosira spp. on 24 DoC appears to be related to the grazing activity of UID 2 .

Similarly, planktonic ciliates comprising mainly Dadayiella acuta, Tintinnopsis minuta, Strombidium caudatum, Euplotes spp. and Eutintinnus elongatus recorded in this study are known to be vigorous grazers of phytoplankton (Pierce \& Turner 1993, Tillmann 2004). Their lower abundance throughout this culture

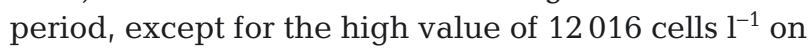
$96 \mathrm{DoC}$, is probably related to the more abundant availability of phytoplankton, which many ciliates are known to feed upon (Liu et al. 2018). Nearly all species of Strombidium are suspension feeders, feeding mainly on larger-sized diatoms (Fenchel 1968). A high abundance of $S$. caudatum and phytoplankton towards the end of shrimp culture is reflective of their intense grazing activity. Higher abundance of Euplotes spp. on 96 DoC could be related to bacterivory, as they are known preferential grazers of bacteria attached to surfaces (Sieburth 1979), especially those associated with the decomposition of animal and plant tissues (Fenchel 1968). The higher abundance of ciliates at the end of the culture period might be in response to higher inputs of organic matter (Decamp et al. 2007, Melo et al. 2010), rapid reproduction rates and short generation times as well as their ability to use a large spectrum of food resources (Capriulo \& Carpenter 1983, Capriulo et al. 2002, Urrutxurtu 2004)

Higher abundances of Eutreptiella marina are associated with nutrient enrichment (Urrutxurtu 2004), and the rapid changes in abundances could be due to the grazing impact of ciliates (Epstein et al. 1992). Eutreptiella sp. are mixotrophs which feed on eubacteria and Synechococcus sp. (Yoo et al. 2018) and employ a range of nutritional modes from osmotrophy to phagotrophy, enabling them to exploit both inorganic and organic resources (Müllner et al. 2001). The growth of Eutreptiella sp. far exceeds the grazing pressure by mesozooplankton when nutrients are not limiting, as in the case of shrimp ponds (Olli et al. 1996). In the coastal waters of China, blooms of Eutreptiella gymnastica coincided with high phosphate concentrations (Xu et al. 2012). Invertebrate metazoans such as copepod nauplii and copepodites, juvenile ostracods, decapod larvae and polychaetes, which contributed $20 \%$ to the microzooplankton abundance in the present study, are also known to be potential grazers of phytoplankton (Berggreen et al. 1988). Since microzooplankton grazing can remove up to $50 \%$ of the stocks of small phytoplankton (Zhang et al. 2011) and $>90 \%$ of dinoflagellate production (Epstein et al. 1992), the preponderance of microzooplankton in our shrimp ponds would have exerted positive control on the phytoplankton bloom and prevented the latter from reaching undesirable proportions. In addition, predation of the microzooplankton by shrimps (Coman et al. 2003) in turn results in the transfer of a significant proportion of the nutrients from natural biota to the shrimp tissue (Anderson et al. 1987). Based on previous studies (Calbet \& Landry 2004) and the abundances observed in this study $\left(10^{5}\right.$ ind. $\left.\mathrm{l}^{-1}\right)$, there is little doubt that microzooplankton forms a significant component of the natural biota of shrimp ponds and are a key link between phytoplankton and shrimps.

By virtue of their sensitivity to environmental changes, plankton communities are often considered excellent indicators of water quality ( $\mathrm{Li}$ et al. 2009). During the culture period, higher abundances of diatoms, dinoflagellates and ciliates coincided with very low species richness and evenness. Lower phytoplankton diversity $(<1.6)$ observed in the shrimp ponds compared to the coastal waters is attributable to chlorination of the seawater for the initial filling, zero-water exchange and dominance of 3 plankton species. In shrimp ponds adjoining Hangzhou Bay, nitrogen and phosphorus load were found to strongly 
influence the proliferation of Chlorophyta blooms and low phytoplankton diversity (Ni et al. 2018).

CCA analysis, which was performed to analyze the relationship between phytoplankton and environmental variables and to understand the main driving factors of phytoplankton community structure, suggested that many centric diatoms (Ceratualina pelagica, Cyclotella ocular, Dactyliosolen fragilissimus and Leptocylindrus minimum) and pennate diatoms (Achnanthes frigidus, Amphiprora paludosa, Diploneis suborbicularis and T. nitzschioides) were growing under high nitrate and ammonium conditions during the first month of shrimp culture. Since a biosecured zero-water exchange system of shrimp farming was followed in the present study, the increasing temperature led to a concomitant increase in salinity, triggering the bloom of the centric diatom Thalassiosira spp. and consequently causing a decrease in DO levels. As 2 species of Thalassiosira sp. were the main contributors to the high biomass of phytoplankton at the end of the culture period and were negatively correlated with nitrate and ammonium, it indicates that the phytoplankton biomass was related to the removal of nitrogen. Though nitrogen is an essential element for phytoplankton growth, and almost all chlorophyll-containing algae grow either on nitrate or ammonium (Syrett 1981), diatom growth is particularly promoted by inorganic nitrogen sources (Robert et al. 1986). Besides providing food, shade and increased oxygen levels and preventing the growth of undesirable benthic algae, reduction in toxic ammonia concentrations by diatom blooms have been documented in shrimp ponds (Chien 1992, Burford 1997).

As the shrimp culture and build-up of the algal biomass progressed, excess phosphate derived from the decomposition of shrimp feed favored the bloom of a semi-heterotrophic euglenoid unarmored flagellate, E. marina and of a few dinoflagellates. The rapid growth of E. gymnastica and dinoflagellates in enriched phosphate conditions was also observed in other studies (Xu et al. 2012, Barcelos e Ramos et al. 2017). Increased turbidity due to higher suspended matter in shrimp ponds may stimulate picoplankton abundance, which can even dominate the phytoplankton community (Burford 1997, Lucas et al. 2010); however, this aspect was not addressed in the present study but will definitely be considered in future investigations.

Low diversity of plankton communities and the dominance of particular species indicates that the shrimp ponds in our study had the tendency to become hypernutrified. However, this study has shown that the effective uptake of nutrients through increased abundance of desirable diatoms and their control by microzooplankton with the progression of the culture helped to maintain the water quality and consequently contributed to good shrimp yield. Many studies have indicated that mixtures of diatoms and flagellates have produced good results in terms of shrimp growth and survival (Gaxiola et al. 2010). In addition, at harvest the undesirable environmental impact due to the discharge of pond water into the coastal waters would be significantly lower.

Acknowledgements. The authors are thankful to the Director, CSIR-National Institute of Oceanography, Goa (India), for encouragement and facilities. Financial support for this study came from project No. PSC0206 of CSIR-NIO (India). The authors are also thankful to the 4 anonymous reviewers for their valuable suggestions in improving the manuscript. This represents Contribution No. 6466 of the CSIR-National Institute of Oceanography, Goa India.

\section{LITERATURE CITED}

Abdelrahman HA, Abebe A, Boyd CE (2019) Influence of variation in water temperature on survival, growth and yield of Pacific white shrimp Litopenaeus vannamei in inland ponds for low salinity culture. Aquacult Res 50: 658-672

Alonso-Rodriguez R, Páez-Osuna F (2003) Nutrients, phytoplankton and harmful algal blooms in shrimp ponds: a review with special reference to the situation in the Gulf of California. Aquaculture 219:317-336

Anderson RK, Padeer PL, Lawrence A (1987) A ${ }^{13} \mathrm{C} /{ }^{12} \mathrm{C}$ tracer study of the utilization of presented feed by a commercially important shrimp Penaeus vannamei in a pond grow-out system. J World Aquacult Soc 18:148-155

Argue BJ, Arce SM, Lotz JM, Moss SM (2002) Selective breeding of Pacific white shrimp (Litopenaeus vannamei) for growth and resistance to Taura syndrome virus. Aquaculture 204:447-460

Barcelos e Ramos J, Schulz KG, Voss M, Narciso Á and others (2017) Nutrient-specific responses of a phytoplankton community: a case study of the North Atlantic Gyre, Azores. J Plankton Res 39:744-761

Becker EW (2004) Microalgae for aquaculture. The nutritional value of microalgae for aquaculture. In: Richmond A (ed) Handbook of microalgal culture. Biotechnology and applied phycology. Blackwell Science, Ames, IA, p 380-391

* Berggreen U, Hansen B, Kiørboe T (1988) Food size spectra, ingestion and growth of the copepod Acartia tonsa: implications for the determination of copepod production. Mar Biol 99:341-352

Boyd CE (1990) Water quality in ponds for aquaculture. Auburn University, Alburn, AL

Boyd CE (1995) Soils in pond aquaculture. In: Bottom soils, sediment, and pond aquaculture. Chapman \& Hall, London, p 1-9

Boyd CE (1999) Aquaculture sustainability and environmental issues. World Aquacult 30:10-13 
Briggs MRP, Funge-Smith SJ (1994) A nutrient budget of some intensive marine shrimp ponds in Thailand. Aquacult Fish Manage 5:789-811

Brown MR, Jeffrey SW, Volkman JK, Dunstan GA (1997) Nutritional properties of microalgae for mariculture. Aquaculture 151:315-331

Burford M (1997) Phytoplankton dynamics in shrimp ponds. Aquacult Res 28:351-360

Burford MA, Lorenzen K (2004) Modeling nitrogen dynamics in intensive shrimp ponds: the role of sediment remineralization. Aquaculture 229:129-145

Burford MA, Williams KC (2001) The fate of nitrogenous waste from shrimp feed. Aquaculture 198:79-93

* Burford M, Thompson PJ, McIntosh RP, Bauman RH, Pearson DC (2003) Nutrient and microbial dynamics in highintensity, zero-exchange shrimp ponds in Belize. Aquaculture 219:393-411

* Calbet A, Landry MR (2004) Phytoplankton growth, microzooplankton grazing and carbon cycling in marine systems. Limnol Oceanogr 49:51-57

Capriulo GM, Carpenter EJ (1983) Abundance, species composition and feeding impact of tintinnid micro-zooplankton in Central Long Island Sound. Mar Ecol Prog Ser 10:277-288

Capriulo GM, Smith G, Troy R, Wikfors GH, Pellet J, Yarish C (2002) The planktonic food web structure of a temperate zone estuary, and its alteration due to eutrophication. Hydrobiologia 475/476:263-333

Cardozo AP, Bersano JGF, Amaral WJA (2007) Composition, density and biomass of Litopenaeus vannamei (Decapoda: Penaeidae) in southern Brazil. Braz J Aquat Sci Technol 11:13-20

Casé M, Leça EE, Leitão SN, Sant'Anna EE, Schwamborn R, de Moraes ATJ (2008) Plankton community as an indicator of water quality in tropical shrimp culture ponds. Mar Pollut Bull 56:1343-1352

Castillo-Soriano FA, Ibarra-Junquera V, Escalante-Minakata P, Mendoza-Cano O, Ornelas-Paz JJ, Almanza-Ramírez JC, Meyer-Willerer AO (2013) Nitrogen dynamics model in zero water exchange, low salinity intensive ponds of white shrimp, Litopenaeus vannamei, at Colima, Mexico. Lat Am J Aquat Res 41:68-79

Catalogue of diatoms (1985) In: Constance AS, Carroll SE, Hillman NS, Janal MJ, Vancouvering JA (eds) The Ellis and Messina Catalogues of Micropaleontology, Book 1 \& 2. Micropaleontology Press, New York, NY

Chien YH (1992) Water quality requirements and management for marine shrimp culture. In: Wyban J (ed) Proceedings of the Special Session on Shrimp Farming. World Aquaculture Society, Baton Rouge, LA, p 30-42

Coman FE, Connolly RM, Preston NP (2003) Zooplankton and epibenthic fauna in shrimp ponds: factors influencing assemblages dynamics. Aquacult Res 34:359-371

Coutteau P (1996) Micro-algae. In: Lavens P, Sorgeloos P (eds) Manual on the production and use of live food for aquaculture. FAO Fisheries Technical Paper No. 361. FAO, Rome, p 7-48

Cremen MCM, Martinez-Goss MR, Corre VL Jr, Azanza RV (2007) Phytoplankton bloom in commercial shrimp ponds using green-water technology. J Appl Phycol 19:615-624

D'Silva MS, Anil AC, D'Costa PM (2011) An overview of dinoflagellate cysts in recent sediments along the west coast of India. Indian J Geo-Mar Sci 40:697-709

Dall W (1968) Food and feeding of some Australian penaeid shrimps. FAO Fish Rep 57:251-258
Daniels HV, Boyd CE (1993) Nitrogen, phosphorus, and silica fertilization of brackish water ponds. J Aquacult Trop 8:103-110

Dawes CJ (1981) Marine Botany. John Wiley \& Sons, New York, NY

Decamp O, Conquest L, Cody J, Forster I (2007) Effect of shrimp stocking density on size-fractionated phytoplankton and ecological groups of ciliated protozoa within zero-water exchange shrimp culture systems. J World Aquacult Soc 38:395-406

Desikachary TV, Prema P (1987) Diatoms from the Bay of Bengal. In: Desikachary TV (ed) Atlas of diatoms, Vol 3. Madras Science Foundation, Madras p 1-10, plates 221-223

Desikachary TV, Ranjithadevi KA (1986) Marine fossil diatoms from India and Indian Ocean Region. In: Desikachary TV (ed) Atlas of diatoms, Vol 3. Madras Science Foundation, Madras, plates 1-77

Desikachary TV, Gowthaman S, Latha Y (1987) Diatom flora of some sediments from the Indian Ocean Region. In: Desikachary TV (ed) Atlas of diatoms, Vol 3 Madras Science Foundation, Madras, plates 78-221

Epstein SS, Burkovsky IV, Shiaris MP (1992) Ciliate grazing on bacteria, flagellates, and microalgae in a temperate zone sandy tidal flat: ingestion rates and food niche partitioning. J Exp Mar Biol Ecol 165:103-123

FAO (2018) The state of world fisheries and aquaculturemeeting the sustainable development goals. FAO, Rome

Fenchel T (1968) The ecology of marine microbenthos. II. The food of marine benthic ciliates. Ophelia 5:73-121

Fernandes SO, Kulkarni SS, Shirodkar RR, Karekar S and others (2010) Water quality and bacteriology in an aquaculture facility equipped with a new aeration system. Environ Monit Assess 164:81-92

*Gaxiola G, Gallardo P, Simôes N, Cuzon G (2010) A red shrimp, Farfantepenaeus brasiliensis (Latreille, 1817), larvae feeding regime based on live food. J World Aquacult Soc 41:402-410

*Ge H, Li J, Chang Z, Chen P, Shen M, Zhao F (2016) Effect of microalgae with semi-continuous harvesting on water quality and zootechnical performance of white shrimp reared in the zero water exchange system. Aquacult Eng 72-73:70-76

Gordon N, Neori A, Shpigel M, Lee J, Harpaz S (2006) Effect of diatom diets on growth and survival of the abalone Haliotis discushannai postlarvae. Aquaculture 252:225-233

Guan Y, Yu Z, Li C (2003) The effects of temperature on white spot syndrome infections in Marsupenaeus japonicus. J Invertebr Pathol 83:257-260

Guillard RRL, Kilham P (1977) The ecology of marine planktonic diatoms. In: Werner D (ed) The biology of diatoms. Blackwell Scientific Publications, Oxford, p 372-469

Hada Y (1938) Studies on tintinnids from the western tropical Pacific. J Pac Sci 6:87-190

Hodgkiss IJ (2001) The N:P ratio revisited. In: Hoand KC, Wang ZD (eds) Prevention and management of harmful algal blooms in the South China Sea. School of Science and Technology, The Open University of Hong Kong, p 344-355

* Izquierdo M, Forster I, Divakaran S, Conquest L, Decamp O (2006) Effect of green and clear water and lipid source on survival, growth and biochemical composition of Pacific white shrimp Litopenaeus vannamei. Aquacult Nutr 12: 192-202

Joshi J, Srisala J, Viet HT, Truong VH and others (2014) 
Variation in Vibrio parahaemolyticus isolates from a single Thai shrimp farm experiencing an outbreak of acute hepatopancreatic necrosis disease (AHPND). Aquaculture 428-429:297-302

Jyothibabu R (2004) Ecobiography, spatial and temporal variations of microzooplankton along the east coast of India. PhD thesis, Cochin University, Kochi

Keawtawee T, Fukami F, Songsangjinda P, Muangyao P (2012) Nutrient, phytoplankton and harmful algal blooms in the shrimp culture ponds in Thailand. Kuroshio Sci 5: 129-136

Lacerda LD, Vaisman AG, Maia LP, Silva CAR, Cunha EMS (2006) Relative importance of nitrogen and phosphorus emissions from shrimp farming and other anthropogenic sources for six estuaries along the NE Brazilian coast. Aquaculture 253:433-446

Lemonnier H, Lantoine F, Courties C, Guillebault D and others (2016) Dynamics of phytoplankton communities in eutrophying tropical shrimp ponds affected by vibriosis. Mar Pollut Bull 110:449-459

KLemonnier H, Hochard S, Nakagawa K, Courties C, Rodier M (2017) Response of phytoplankton to organic enrichment and shrimp activity in tropical aquaculture ponds: a mesocosm study. Aquat Microb Ecol 80:105-122

Li WK, McLaughlin FA, Lovejoy C, Carmack EC (2009) Smallest algae thrive as the Arctic Ocean freshens. Science 326:539

Liu Q, Lu B, Song X, Li Y and others (2018) Recovery of ciliated protozoan communities in response to environmental change in a shrimp-farming pond in southern China. J Mar Biol Assoc UK 98:1263-1272

* Lorenzen K (1999) Nitrogen recovery from shrimp pond effluent, dissolved nitrogen removal has greater overall potential than particulate nitrogen removal, but requires higher rates of water exchange than presently used. Aquacult Res 30:923-927

Lucas R, Courties C, Herbland A, Goulletquer P, Marteau AL, Lemonnier H (2010) Eutrophication in a tropical pond: understanding the bacterioplankton and phytoplankton dynamics during a vibriosis outbreak using flow cytometric analyses. Aquaculture 310:112-121

Malone TC (1980) Algal size. In: Morris (ed) The physiological ecology of phytoplankton. Blackwell Scientific Publications, Oxford, p 433-463

Martinez-Cordova LR, Porchas-Cornejo MA, Villarreal-Colmenares H, Calderon-Perez JA (1998) Effect of aeration on chlorophyll $a$, zooplankton, and benthos in yellow leg shrimp, Penaeus californiensis ponds. J Appl Aquacult 8: $17-23$

Melo MP, Carvalheiro JMO, Cordeiro TA, Queiroz AR, Prado JP, Borges IF (2010) Phytoplanktonic composition of three cultivation systems used in Litopenaeus vannamei (Boone, 1931) marine shrimp farms. Acta Sci Biol Sci 32:223-228

Mohanty RK, Ambast SK, Panigrahi P, Mandal KG (2018) Water quality suitability and water use indices: useful management tools in coastal aquaculture of Litopenaeus vannamei. Aquaculture 485:210-219

Moss SM (1994) Growth rates, nucleic acid concentrations and RNA/DNA ratios of juvenile white shrimp, Penaeus vannamei Boone, fed different algal diets. J Exp Mar Biol Ecol 182:193-204

* Müllner AN, Angeler DG, Samuel R, Linton EW, Triemer RE (2001) Phylogenetic analysis of phagotrophic, phototrophic and osmotrophic euglenoids by using the nu- clear 18S rDNA sequence. Int J Syst Evol Microbiol 51: 783-791

Ni M, Yuan JM, Mei GZ (2018) Assessment of water quality and phytoplankton community of Litopenaeus vannamei pond in intertidal zone of Hangzhou Bay, China. Aquacult Rep 11:53-58

Nuñez-Pastén A (1988) Crecimiento del camaró n Penaeus vannamei, $P$. stylirostris, $P$. californiensis y su relació $\mathrm{n}$ con factores ambientales (temperatura y salinidad) en las lagunas de Huizache y Caimanero, Sinaloa, México. MSc thesis, Universidad Nacional Autó noma de México, México City

К Olli K, Heiskanen AS, Seppälä J (1996) Development and fate of Eutreptiella gymnastica bloom in nutrient-enriched enclosures in the coastal Baltic Sea. J Plankton Res 18: 1587-1604

Paerl HW, Tucker CS (1995) Ecology of blue-green algae in aquaculture ponds. J World Aquacult Soc 26:109-131

*Páez-Osuna F (2001a) The environmental impact of shrimp aquaculture: causes, effects and mitigating alternatives. Environ Manage 28:131-140

* Páez-Osuna F (2001b) The environmental impact of shrimp aquaculture: a global perspective. Environ Pollut 112: $229-231$

*Páez-Osuna F, Garcia A, Flores-Verdugo F, Lyle-Fritch LP, Alonso-Rodríguez R, Ruiz-Fernández AC (2003) Shrimp aquaculture development and the environment in the Gulf of California ecoregion. Mar Pollut Bull 46:806-815

Parry G (1960) Excretion. In: Waterman TH (ed) The physiology of Crustacea, Vol. 1. Academic Press, New York, NY, p 341-366

Parsons IR, Malta Y, Lalli CM (1984) A manual of chemical and biological methods for seawater analysis. Pergamon Press, Oxford, p 63-104

*Pednekar SM, Kerkar V, Matondkar SGP (2014) Spatio-temporal distribution in phytoplankton community with distinct salinity regimes along the Mandovi estuary, Goa, India. Turk J Bot 38:800-818

* Pielou EC (1966) The measurement of diversity in different types of biological collections. J Theor Biol 13:131-144

* Pierce RW, Turner JT (1993) Global biogeography of marine tintinnids. Mar Ecol Prog Ser 94:11-26

* Ponce-Palafox J, Martinez-Palacios CA, Ross LG (1997) The effects of salinity and temperature on the growth and survival rates of juvenile white shrimp, Penaeus vannamei, Boone, 1931. Aquaculture 157:107-115

* Prakash A, Rashid MA (1968) Influence of humic substances on the growth of marine phytoplankton: dinoflagellates. Limnol Oceanogr 13:598-606

Robert JM, Vincendeau ML, Maestrini SY, Marion A (1986) Prises simultanees de I'azote mineral et de l'uree par les algues unicellulaires des claires ostreicoles: effet de la source d'azote sur la nature du peuplement. CR Acad Sci 303:167-170

Koy SS, Pal R (2015) Microalgae in aquaculture: a review with special references to nutritional value and fish dietetics. Proc Zool Soc 68:1-8

Koy LA, Davis DA, Saoud IP, Boyd CA, Pine HJ, Boyd CE (2010) Shrimp culture in inland low salinity waters. Rev Aquacult 2:191-208

* Rubright JS, Harrel JL, Holcomb HW, Parker JC (1981) Responses of planktonic and benthic communities of fertilizer and feed applications in shrimp mariculture ponds. J World Maricult Soc 12:281-299

Sánchez-Martínez JG, Aguirre-Guzmán G, Mejía-Ruiz H 
(2007) White spot syndrome virus in cultured shrimp: a review. Aquacult Res 38:1339-1354

Sanders JG, Cibik SJ, D'Elia CF, Boynton WR (1987) Nutrient enrichment studies in a coastal plain estuary: changes in phytoplankton species composition. Can J Fish Aquat Sci 44:83-90

Santhana Kumar V, Pandey PK, Anand T, Bhuvaneswari R, Kumar S (2017) Effect of periphyton (aquamat) on water quality, nitrogen budget, microbial ecology, and growth parameters of Litopenaeus vannamei in a semi-intensive culture system. Aquaculture 479:240-249

Shaari AL, Surif M, Latiff FA, Omar WMW, Ahmad MN (2011) Monitoring of water quality and microalgae species composition of Penaeus monodon ponds in Pulau Pinang, Malaysia. Trop Life Sci Res 22:51-69

Shan H, Obbard J (2001) Ammonia removal from prawn aquaculture water using immobilized nitrifying bacteria. Appl Microbiol Biotechnol 57:791-798

Shannon CE, Weaver W (1963) The mathematical theory of communications. University of Illinois Press, Urbana, IL

Sherr B, Sherr F (2007) Heterotrophic dinoflagellates: a significant component of microzooplankton biomass and major grazers of diatoms in the sea. Mar Ecol Prog Ser 352:187-197

Sieburth JMcN (1979) Sea microbes. Oxford University Press, New York, NY

Smith VH (1983) Low nitrogen to phosphorus ratio favors dominance by blue-green algae in lake phytoplankton. Science 221:669-671

Smith DW (1985) Biological control of excessive phytoplankton growth and the enhancement of aquaculture production. Can J Fish Aquat Sci 42:1940-1945

Smith PT (1994) Sedimentation in prawn ponds: the role of microalgae. In: Science, management and sustainability of marine habitats in the $21^{\text {st }}$ century. Australian Marine Science Association Annual Conference, 3-11 July 1994, Townsville. James Cook University, Australian Marine Science Association, Australian Coral Reef and International Society for Reef Studies, p 70 (Abstract)

Sommer U (1989) The role of competition for resources in phytoplankton species succession. In: Sommer U (ed) Plankton ecology - succession in plankton communities. Springer, Berlin, p 57-106

Songsangjinda P, Yamamoto T, Fukami K, Keawtawee T (2006) Importance of controlling community structure of living organisms in intensive shrimp culture ponds. Coast Mar Sci 30:91-99

Stickney RR (2005) Aquaculture: an introductory text. CABI, Cambridge, MA

Subramanyan R (1968) Memoir 2: the Dinophyceae of the Indian Sea. Marine Biological Association of India, Mandapam Camp

Subramanyan R, Sarma AH (1961) Studies on the phytoplankton of the West Coast of India. Indian J Fish 7 : 307-336

Syrett PJ (1981) Nitrogen metabolism of microalgae. Can Bull Fish Aquat Sci 210:182-210

Tacon A, Cody JJ, Conquest LD, Divakaran S, Forster IP,

Editorial responsibility: Louis Lebel,

Chiang Mai, Thailand
Decamp OE (2002) Effect of culture system on the nutrition and growth performance of Pacific white shrimp, Litopenaeus vannamei (Boone) fed different diets. Aquacult Nutr 8:121-137

ter Braak CJF, Šmilauer P (2002) CANOCO reference manual and CanoDraw for Windows user's guide - software for canonical community ordination, version 4.5. Microcomputer Power, Ithaca, NY

*Tillmann U (2004) Interactions between planktonic microalgae and protozoan grazers. J Eukaryot Microbiol 51: 156-168

Tomas CR (1997) Identifying marine phytoplankton. Academic Press, San Diego, CA

* Tseng KF, Huang JS, Liao IC (1991) Species control of microalgae in an aquaculture pond. Water Res 25:1431-1437

Underwood AJ (1997) Experiments in ecology: their logical and interpretation using analysis of variance. Cambridge University Press, Cambridge

Urrutxurtu I (2004) Seasonal succession of tintinnids in the Nervio'n river estuary, Basque Country, Spain. J Plankton Res 26:307-314

Varadharajan D, Pushparajan N (2013) Food and feeding habits of aquaculture candidate a potential crustacean of Pacific white shrimp Litopenaeus vannamei, southeast coast of India. J Aquac Res Dev 4:1-5

Vin HP (2017) Contribution of natural plankton to the diet of white leg shrimp Litopenaeus vannamei (Boone, 1931) post-larvae in fertilized pond conditions. MSc dissertation, University of Gent

Volkman J, Brown M (2006) Nutritional value of microalgae and applications. In: Subba Rao DV (ed) Algal cultures: analogues of blooms and applications, Vol 1. CABI, Wallingford, p 407-457

Waite AM, Gustafsson O, Lindahl O, Tiselius P (2005) Linking ecosystem dynamics and biogeochemistry: sinking fractionation of organic carbon in a Swedish fjord. Limnol Oceanogr 50:658-671

Welch PS (1952) Limnology. McGraw Hill, New York, NY

* Xu N, Pang S, Shan T, Liu F, Zhao X, Gao S (2012) Molecular identification and culture trials of Eutreptiella gymnastica (Eutreptiales, Euglenophyceae). Chin J Oceanology Limnol 30:446-455

Yoo YD, Seong KA, Kim HS, Jeong HJ and others (2018) Feeding and grazing impact by the bloom-forming euglenophyte Eutreptiella eupharyngea on marine eubacteria and cyanobacteria. Harmful Algae 73:98-109

* Yusoff FM, Zubaidah MS, Matias HB, Kwan TS (2002) Phytoplankton succession in intensive marine shrimp culture ponds treated with a commercial bacterial product. Aquacult Res 33:269-278

Zhang L, Sun Y, Zhao C, Wang Y, Tan M (2011) Study on microzooplankton grazing in shrimp pond among middle and late shrimp culture period. Shengtai Xuebao Acta Ecol Sin 31:2046-2052

Kiemann DA, Walsh WA, Saphore EG, Fulton-Bennett K (1992) A survey of water quality characteristics of effluent from Hawaiian aquaculture facilities. J World Aquacult Soc 23:180-191

Submitted: March 29, 2019; Accepted: October 21, 2019

Proofs received from author(s): November 25, 2019 